\title{
IDENTIDADE IMIGRANTE EM CANÇÕES: A CONSTRUÇÃO DO SENTIDO BASEADA EM FRAMES
}

\section{IMMIGRANT IDENTITY IN SONGS: THE CONSTRUCTION OF SENSE BASED ON FRAMES}

\author{
Larissa Barros Souza ${ }^{1}$ \\ Ednaldo Feijó de Souza ${ }^{2}$ \\ Talita Mirella Ferreira Silva ${ }^{3}$ \\ Rodrigo Slama Ribas ${ }^{4}$ \\ Maurivan de Barros Candido 5
}

RESUMO: A música popular é um artefato midiático através do qual são tramitados socialmente conceitos, valores, atitudes e estratégias de identidade individual e coletiva. Através das letras, podemos refletir sobre assuntos importantes, nos emocionamos, reconhecemos a uma identidade cultural. $\mathrm{Na}$ música universal, temas que vão desde o amor à exploração do trabalho se presentificam, e a identidade dos imigrantes fica de fora do escopo temático das canções. Este trabalho é uma relação entre as áreas de Língua Inglesa, uma vez que todas as canções estudadas são deste idioma, é de Língua Portuguesa, na questão da interpretação e análise de construção do sentido. Assim, para compreender um pouco mais da identidade dos imigrantes e demais aspectos sociais elucidados pela linguagem, esta pesquisa se propôs a investigar como se dá a construção de sentido das canções que trazem à luz o universo do povo imigrante. Esta pesquisa tem por natureza ser qualitativa. Em primeiro lugar, investigaremos as dentre as mais tocadas do cenário pop internacional nos últimos 20 anos que elucidam, de alguma maneira, a identidade dos imigrantes. Inicialmente, investigaremos canções de sucesso mundial, de grandes artistas ou bandas reconhecidas internacionalmente, que são facilmente reconhecidas pelo público. Para análise da construção de sentido, privilegiaremos o domínio conceptual básico do frame. Estes tipos frame são associados a expressões ou a itens lexicais e, ao se relacionarem com outros frames, auxiliam na construção do significado. Ao associarmos os itens lexicais "flores", "choro" e "caixão", elucidamos o frame de velório, por exemplo. A partir dos critérios definidos pela pesquisadora bolsista, que buscou pelas músicas mais tocadas na plataforma YouTube, chegamos às

\footnotetext{
I Estudante em informática do Instituto Federal Sertão Pernambucano - Campus Ouricuri. Bolsista do Programa Institucional de Bolsas de Iniciação Científica (PIBIC Jr) Edital 55/2018.

2 Professor EBTT - Lingua Inglesa - Instituto Federal Sertão Pernambucano - Campus Ouricuri. Especialista em Tradução Inglês-português/ Português - Inglês Universidade Federal de PernambucoUFPE.

3 Técnica em Assuntos Educacionais - Instituto Federal Sertão Pernambucano - Campus Ouricuri. Especialista em Língua Portuguesa - (URCA - Universidade Regional do Cariri).

4 Professor EBTT - Língua Portuguesa - Instituto Federal Sertão Pernambucano - Campus Ouricuri. Doutor em Estudos da Linguagem - Linguística Teórica e Descritiva pela Universidade Federal do Rio Grande do Norte,- UFRN.

5 Professor de Língua Inglesa - Centro de Ensino de Idiomas FISK, Unidade Salgueiro - PE. Especialista em Ensino de Língua Inglesa ( Faculdade Única - Salgueiro -PE)
} 
seguintes canções para compor o corpus desta pesquisa: a) Immigrant Song, Led Zeppelin; b) American Oxygen, Rihanna; c) Prayer of the Refugee, Rise Against, d) Immigration Man, Crosby \& Nash, e) Ellis Islans, Mary Black, f) America, Neil Diamond, g) Immigration Blues, Chris Rea, h) City of Immigrants, Steve Earle e i) The Refugee, U2. Tomando como base os elementos analisados, é possível afirmar que a figura imigrante é uma figura submissa a condições sociais e de gênero. É um ser que não tem o domínio de seu próprio destino e que aguarda sempre a chegada de outra pessoa, pela indefinição tonal, que espessa toda uma ampla gama de transferências interpretativas, colaborando densa e criticamente para o pensamento recente sobre imigração no país.

Palavras-chave: Música Popular; Frame; Identidade imigrante

ABSTRACT: Popular music is a mediatic artifact which socially conveys concepts, values, attitudes, and collective and individual identity strategies. Through lyrics, we may reflect upon important topics, get emotional, acknowledge a cultural identity. In universal music, themes ranging from love to work exploitation are presented, and the immigrants' identity is put aside from the thematic scope of songs. This paper is a relationship between the English Language, once all the songs used for this study belong to this language, and Portuguese Language, when interpreting and analyzing meaning construction are in question. Thus, to shed some light on immigrants' identities and other social aspects enlightened by language, this research aimed at investigating the way construction of the meaning of songs concerning the immigrants' universe happens. This research has a qualitative nature. First of all, worldwide success songs by artists or bands known by a wide audience will be investigated. To analyze the construction of meaning, the basic conceptual mastery of frame will be privileged. These frame types are associated with expressions or lexical items and, by relating to other frames, help in the construction of meaning. By associating the lexical items "flowers", "crying" and "coffin", for instance, the frame of funeral service is illustrated. Starting from the criteria defined by the researcher, who searched songs to establish the corpus of this research: a) Immigrant Song, Led Zeppelin; b) American Oxygen, Rihanna; c) Prayer of the Refugee, Rise Against, d) Immigration Man, Crosby \& Nash, e) Ellis Islans, Mary Black, f) America, Neil Diamond, g) Immigration Blues, Chris Rea, h) City of Immigrants, Steve Earle e i) The Refugee, U2. Based on the elements which were analyzed, it is possible to affirm the immigrant figure is submissive to gender and social conditions. It is a figure who does not master his fate and who is always waiting for somebody else to come due to his tonal vagueness, thickening a wide range of interpretative transferences, densely and critically collaborating for recent thoughts about immigration all over the country.

Keywords: Popular Music; Frame, Immigrant identity.

\section{INTRODUÇÃO}

A canção é, certamente, a manifestação literária mais presente no nosso cotidiano atualmente. Através das letras, podemos refletir sobre assuntos importante, nos emocionamos, reconhecemos a uma identidade cultural. Na música universal, temas que vão desde o amor à exploração do trabalho se presentificam, e a identidade dos imigrantes fica de fora do escopo temático das canções. 
Este trabalho é uma relação entre as áreas de Língua Inglesa, uma vez que todas as canções estudadas são deste idioma, é de Língua Portuguesa, na questão da interpretação e análise de construção do sentido.

Assim, para compreender um pouco mais da identidade dos imigrantes e demais aspectos sociais elucidados pela linguagem, esta pesquisa se propôs a investigar como se dá a construção de sentido das canções que trazem à luz o universo do povo imigrante.

Compreender os processos de construção de sentido é importante, pois é baseado nos discursos que consumimos que nos afiliamos a uma ideia. Toda significação que construímos ou que somos levados a construir passa pela linguagem, passa pela estrutura, passa pelas escolhas lexicais. Deste modo,

a seleção do léxico e a forma de combinarmos palavras durante a produção do discurso devem ser pensadas como estratégias básicas de construção de sentido. (...) algumas evidências de que essas estratégias, apesar de básicas, são suficientes para fornecer os insumos necessários para a construção de sentidos complexos e de diferentes visões de mundo (DUQUE, 2015).

A Linguística Cognitiva se apresenta como umas teorias mais recentes no campo de investigação da linguagem, e apresenta caminhos sólidos para a compreensão da construção de sentido. Isso acontece porque, nesta perspectiva, "as estruturas de conhecimento, que guiam nossas percepções, são, em grande medida, reguladas por uma contínua interação entre práticas socioculturais, esquemas cognitivos, capacidades corporais e linguagem" (DUQUE \& COSTA, 20II, p. 17). Assim, para cumprirmos os objetivos deste trabalho de forma satisfatória, a Linguística Cognitiva é indispensável.

\section{REVISÃO DA LITERATURA}

Foi verificado no banco de teses e dissertações da capes palavras-chave que indicassem um trabalho que envolvesse a teoria e o objeto em questão, no entanto, nada foi encontrado. Este trabalho, portanto, apresenta em si um ineditismo.

\section{MATERIAL E MÉTODOS}

Esta pesquisa tem por natureza ser qualitativa. Em primeiro lugar, investigaremos as dentre as mais tocadas do cenário pop internacional nos últimos 20 anos que elucidam ${ }^{6}$, de alguma maneira, a identidade dos imigrantes. Inicialmente, investigaremos canções de

\footnotetext{
${ }^{6}$ Grifo dos autores.
} 
sucesso mundial, de grandes artistas ou bandas reconhecidas internacionalmente, que são facilmente reconhecidas pelo público.

Para análise da construção de sentido, privilegiaremos o domínio conceptual básico do frame, presente em DUQUE $(2015,2017)$. Estes tipos frame são associados a expressões ou a itens lexicais e, ao se relacionarem com outros frames, auxiliam na construção do significado. Ao associarmos os itens lexicais "flores", "choro" e "caixão", elucidamos o frame de velório, por exemplo.

Além disso, como uma das preocupações da Linguística Cognitiva é entender como o cérebro constrói e armazena significados, precisamos atentar a um conceito muito importante, a categorização, que é "toda atividade mental que nos permite organizar, em termos de classes, a imensa variedade de entidades que constituem o ambiente externo, dando-lhes significações particulares" (DUQUE \& COSTA, 20II, p. 19). Não conseguiríamos, sem a criação de categorias que criamos a partir dos traços em comum das entidades que nos cercam, guardar tudo que está em nossa volta. O que fazemos é, ao invés de criar uma gaveta para cada significado, utilizar grandes baús para organizar entidades afins.

Para o desenvolvimento desta pesquisa, a noção de frames é muito importante. De acordo com Duque (2015), os frames são responsáveis, como mecanismos cognitivos, pelos nossos pensamentos, ideias e visões de mundo, ou seja, pensamos com frames. Não se pode construir nenhum significado novo sem um frame já estabelecido em determinada cultura

Por esta questão, a Teoria dos Protótipos (ROSCH, 1999; DUQUE, 2002) nos ajuda a organizar os sentidos em relação ao que é mais saliente para o nosso contexto. Ao ouvirmos "ave", pensaremos em algum animal o qual mais se presentifica em nossa realidade, como uma galinha, um pardal ou um papagaio, além disso, eles têm traços prototípicos de aves, com bico, penas e capacidade de voar. Já a avestruz, não possui todos os traços de ave, pois não possui capacidade de voar.

Por estas questões, a LC se apresenta como importante teoria para analisar a construção de sentidos das canções do sertão. Com ela, desenvolveremos um trabalho importante do ponto de vista científico e social, além disso, o nome do IF Sertão-PE figurará entre os grupos e pesquisadores de LC no Brasil.

As canções foram traduzidas para melhor compreensão. A tradução foi feita pela bolsista e supervisionada pelo professor coordenador do projeto. 


\section{RESULTADOS E DISCUSSÃO}

A partir dos critérios definidos pela pesquisadora bolsista, que buscou pelas músicas mais tocadas na plataforma You Tube, chegamos às seguintes canções para compor o corpus desta pesquisa: a) Immigrant Song, Led Zeppelin; b) American Oxygen, Rihanna; c) Prayer of the Refugee, Rise Against, d) Immigration Man, Crosby d Nash, e) Ellis Islans, Mary Black, f) America, Neil Diamond, g) Immigration Blues, Chris Rea, h) City of Immigrants, Steve Earle e i) The Refugee, U2.

Segue a análise de uma das canções selecionadas. Escolhemos esta, pois, de modo geral, as canções apresentam resultados semelhantes e o arquivo iria se tornar longo.

Para melhor compreensão, segue a canção traduzida e toda análise foi feita baseada nesta tradução.

\section{A Refugiada}

$-\mathrm{U}_{2}$

Ela é uma refugiada

Vejo seu rosto

Vejo você me encarando de volta

Ela é uma refugiada

A mãe dela diz que um dia ela vai

Viver na América

De manhã

Ela está esperando

Esperando pelo navio para velejar

Velejar para longe

Seu pai foi pra guerra

Ele vai lutar

Mas não sabe para que

Seu pai foi pra guerra

A mãe dela diz que um dia ele vai

Voltar de longe
Me ajude

Como você pode me ajudar?

À noite

Ela está esperando

Esperando seu homem chegar

E pegar em sua mão

E levá-la para esta terra prometida

Ela tem um rostinho bonito

Mas na época errada

No lugar errado

Ela tem um rostinho bonito

A mãe dela diz que um dia ela vai viver na América

Pois é, América

Ela é uma refugiada

Ela está voltando, voltando

Para te fazer companhia

Para ilustração dos resultados obtidos pelas análises das canções, apresentamos a análise de The Refugee, da banda Irlandesa U2, em tradução para A Refugiada. Lançada em 1993, no álbum War, A Refugiada fala de uma imigrante que deseja ir para a América. Abaixo, segue o gráfico das palavras mais significativas. 


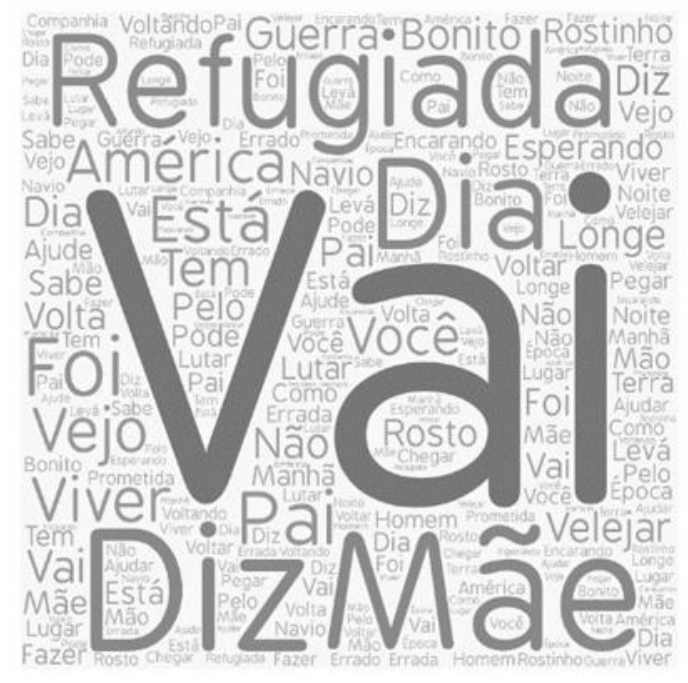

Figura I - Gráfico em nuvem - wordart.com

A palavra com maior número de ocorrência na canção é o verbo 'vai', que indica partida. Além dela, as palavras 'refugiada', 'dia', 'diz' e 'mãe' também aparecem com maior frequência que as demais e, portanto, aparecem com maior destaque no quadro das palavras das canções.

A maior ocorrência do verbo 'ir', em terceira pessoa do futuro do presente, indica a mobilidade na construção do sentido da ideia do que seria um refugiado. Refugiado, segundo a canção, não está, mas irá. Está em movimento, nunca estabelecido, estático. A única permanência é a falta de estabilidade.

A partir da palavra Refugiada, título da canção, aparecem palavras-chave, que auxiliam na compreensão da ideia de Refugiada que vai se criando no desenvolvimento do texto. Segue um quadro com esses blocos de palavras.

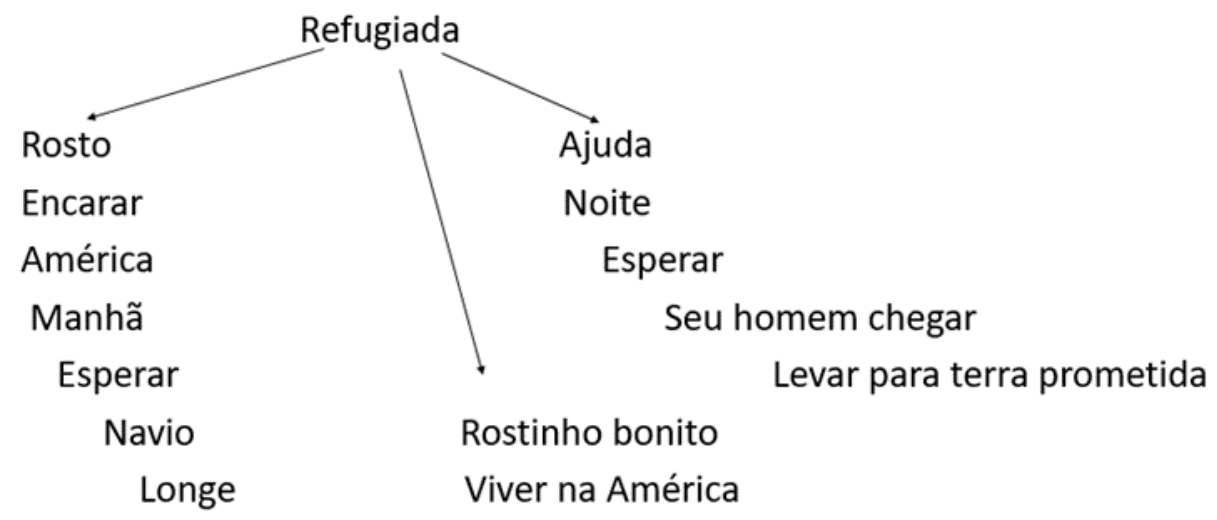

Figura 2 - Esquema em grafo das palavras-chave do texto 
A palavra Refugiada, desencadeia uma série de outras palavra-chave que vão contribuindo para a construção do sentido deste termo. É possível observar mais de uma ocorrência da palavra América. Os EUA eram, à época da canção, o lugar mais procurado pelos imigrantes por conta das oportunidades de emprego e da desvalorização da economia nos países, hoje, emergentes.

Um fato importante a se considerar é a presença de um elemento externo, um homem, que irá levar a Refugiada para a América. Ao trazer a figura masculina, podemos questionar não só o papel do ser imigrante, mas também o papel da mulher e do homem legados pela canção. Além de ser vulnerável por ser imigrante, a Refugiada tem sua condição feminina levada em consideração para a construção de sentido no texto.

\section{Considerações finais}

Tomando como base os elementos analisados, é possível afirmar que a figura imigrante é uma figura submissa a condições sociais e de gênero. É um ser que não tem o domínio de seu próprio destino e que aguarda sempre a chegada de outra pessoa. Além disso, é importante destacar que os EUA são retratados, na canção analisada neste texto, como um ideal de destino e, consequentemente, um sonho de mudança de vida para a Refugiada. A análise prévia das demais canções, apontam, com dito, que elas também seguem esta tendência e evidenciam a figura do imigrante como dependente de outra pessoa para conseguir uma ascensão social.

\section{REFERÊNCIAS}

DUQUE, P. H. Discurso e cognição: uma abordagem baseada em frames. Revista da Anpoll no 39, p. 25-48, Florianópolis, Jul./Ago. 2015.

CÉSAR, C. Respeitem meus cabelos, brancos. 2002. Disponível em $\langle$ https://www.youtube.com/watch?v=nllAkyUoTOs〉 Acesso 25/o6/2019

.; COSTA. M. A. Cognitivismo, corporalidade e construções: novas perspectivas nos estudos da linguagem. Cadernos de Letras da UFF, v. I, p. 87-108, 201 .

FRANÇA, $\mathrm{X}$. Breu. 2016. Disponível em 〈https://www.youtube.com/watch?v=vRTUoJ7dVe8> Acesso 14/o7/2019.

KENEDY, E. Gerativismo. In. MARTELOTTA, M. E. Manual de linguística. São Paulo: Contexto, 20II, p. I27-140.

SLAMA, Rodrigo. Moral e política em (dis)curso: análise baseada em frames de discursos de posse dos presidentes do Brasil dos últimos 20 anos. Tese de doutorado. Disponível em < https://repositorio.ufrn.br/jspui/handle/123456789/27060> Acesso 17/ro/2019. 